\title{
Garden class experiment connotation construction of practice training bases
}

Le Jing LIN

Ningbo City College of \&nbsp; Vocational Technology.

\begin{abstract}
The quickening pace of construction of higher education and the deepening of teaching reform, higher vocational colleges have stepped up investment on construction of practice teaching facilities, experiment practice of improving the hardware environment, however, relative to the rapid growth of teaching in terms of hardware, practice teaching soft environment construction is slower, the connotation construction of practice training bases to ignore, practice teaching management mode as the soul and core of soft environment, is the most fundamental problems in the practice teaching, has brought to the attention of more and more scholars.
\end{abstract}

Key words : Landscape classes; Experimental training bases; The connotation of the construction

Strengthening the connotation construction of practice training bases, it is necessary to strengthen and standardize the laboratory management, straighten out the management procedure, to ensure implement management rules and regulations, to revitalize the existing training resources, improve the utilization efficiency of lab, optimize the laboratory construction and equipment configuration. Under current conditions, the characteristics of higher vocational colleges how to effectively to establish their own internal management mode of practice training bases, completes the connotation of the base construction, the rapid development of practice teaching system, to better meet the needs of the teaching of higher vocational colleges, has become a serious issue in front of higher vocational colleges. This paper mainly in view of the garden class experimental correlation analysis connotation construction of practice training bases.

\section{The main content of landscape connotation the experimental practice base construction}

\subsection{The garden type campus experimental concept connotation of the practice base construction.}

Botanical garden specialty is strong practical a discipline, students need to provide necessary experimental environment, the practice teaching to meet the colleges and universities, the training of specialists in the field of landscape gardening classes teaching task. Training base is the practice teaching system in order to strengthen the students theoretical knowledge jointly set up by the actual professional place, can provide students with practical training experiment and operation, is to improve the students' ability of operating one of the important places, including sites, laboratory equipment, teaching staff, teaching resources management, etc. Experimental practice link is to cultivate

Le Jing LIN: linlejing@nbcc.cn. Fund project: ningbo garden plant development key laboratory project a22008 (2014), a key project of ningbo city professional technology institute (JY1311) 
students' professional quality as well as an important part of the actual operation ability, plays an important role in the professional education.

\subsection{Increase the funds investment,} improve the practice teaching system.

Traditional laboratory due to insufficient funds, some problems such as lack of teaching equipment, cannot effectively carry out the teaching experiment; In the match the project curriculum integration in the training room, the traditional experimental teaching in the lab for the innovation and optimization, the more attention to the cooperation degree of project courses and teaching, to cultivate the students' dialectical thinking. Therefore, college should attach importance to the laboratory construction, increasing investment, perfect laboratory equipment, help to enhance the enthusiasm of students for learning. Schools to improve laboratory in various infrastructure construction, the construction of a comprehensive practice teaching system, and regularly to the laboratory equipment maintenance and update, ensure its role in the practice teaching, and regularly check for updates of laboratory equipment, ensure that the practice teaching work orderly, also need to adjust on the experimental equipment of spending.

\subsection{Strengthen the human resource management, improve the overall service quality.}

Professional education to teacher's requirements in addition to need to have professional quality, at the same time needs to have the practical application of the major of various quality. This requires teachers to the actual production and the enterprise, "practice" can not only came to lectures, but also to step down, is to achieve an important factor to improve students' comprehensive quality. School should attach great importance to the practice of backbone teachers and young teachers, education and vocational education should be strengthened in the course of implementation, vigorously introduce enterprises and technical personnel, improve the level of practice teaching. School attaches great importance to the cooperation between colleges and actively absorb the enterprise high quality education resources.

\subsection{Perfect laboratory management system, strengthening laboratory management standardization.}

Experimental training base management including equipment management, personnel management, curriculum management aspects of content, may adopt "combines unification" appropriate management style, set up perfect laboratory management system, reasonable distribution of managers at all levels, clear responsibilities and division of labor, strengthen the experimental base of normative management. Joint actual play laboratory effectively in the development of students' theoretical knowledge and the role of practice ability, helps to cultivate the practicing ability and specialized quality, strengthen the development of experiment teaching, in order to achieve the purpose of the experiment teaching, help to improve students' comprehensive ability, to adapt to the social development and landscape industry development demand for innovative talents.

2 Garden class experiment reform goals of the construction of the connotation of the practice base

2.1 Introduction of $7 \mathrm{~s}$ on-site management, optimizing experiment site management practice training bases.

$7 \mathrm{~S}$ on-site management sort (Seiri), consolidation (Seiton), cleaning (Seiso), clean (Seikeetsu), quality (Shitsuke), security (safety), and speed/save (speed/saving), due to the first letter of the seven words for $\mathrm{S}$, are referred to as "for $7 \mathrm{~S}$. It is to point to carry out to sorting, reorganization, cleaning, clean, safe, save the content such as related activities, and to improve the quality as the main task. This method is mainly originated from Japan, and showed a 
good application effect. $7 \mathrm{~s}$ on-site management to the botanical garden the experimental practice base site management, helps to cultivate the students' humanistic quality, and improve the efficiency of the experimental practice base site management, help to improve the quality of experimental base management.

2.2 The rectification laboratory setting, strengthening the management of resources and maximum realize resources sharing.

Because money is tight, can put in the laboratory construction funds is relatively small, and landscape architecture experiment is given priority to with agriculture production experiment. So, can consider to build a can accord with the actual situation of school public experimental platform. Through public experimental platform construction, to save the school bought infrastructure funds, and in the same layout and on the basis of unified planning, realize the combination of different professional requirements, will be effective for use in schools on the basis of the experimental teaching equipment purchase, and focus on key construction of professional school, optimizing the allocation of resources and sharing.

2.3The optimizing match the project curriculum integration training rooms and classification of traditional laboratory management, improve the efficiency of management.

Slam the door on the shortcomings in traditional classification of laboratory management, take with the project course to match the integration of laboratory management, and attaches great importance to the professional, practical, advanced, scientific, sharing principle, such as effective for production practice teaching, vocational training, research and development activities. According to the actual production process or in the production process to design practice, help to improve the effectiveness of practice teaching.

\subsection{Strengthen the system construction and realize the scientific management.}

Need attention in the construction of experimental teaching system of teaching, training, implementation of the scientific research and production, the need to build perfect equipment, advanced technology, characteristic, effective operation and production integration of modern practice teaching system, and modern enterprise cooperation, realize the resource sharing, and attaches great importance to the experimental practice base construction, according to the botanical garden the needs of students operation ability and the cultivation of strain capacity.

\section{Landscape connotation the experimental practice base construction key problems to be solved}

3.1 How to build the garden type campus experimental connotation of the practice base construction system.

To enhance investment in experiment teaching, promote the botanical garden specialized teaching level, to promote the deepening of education reform, improve the comprehensive quality of students. Laboratory is an important part in modern school teaching infrastructure, and there are more and more attention to the importance of experimental teaching in school. Landscape gardening classes experiment bases most productive training project implementation, the site has particularity, experimental training project some use of means of production has a certain risk, some will use the toxic drugs, such as agricultural need more strict management. How to management, experiment practice base what management mode and so on all has become a problem to be solved. And now its input and output is out of practice training bases, people traditionally in general will simply "post professional ability" as the goal of practice teaching. Experimental teaching in order to make students in a real environment, increase 
the work experience, do joint theory to practice, but there was some difference of this approach compared with the actual, therefore, independent college can consider to cooperate with enterprises, let the students into the enterprise practice, help to improve the students' actual operation ability, and cultivate social needs of talents. Garden need to meet the engineering surveying and mapping class experiment practice base, landscape sketch operations such as training, can carry on the simulation under the guidance of the teacher project practice, and in the application of knowledge in project management, design and nursery, flower cultivation and management, and other activities.

3.2 How to realize the integration of match the project course training rooms and classification of traditional laboratory management.

School training base in higher vocational education is implement vocational skills training and vocational quality education for students in the best place, campus practice base created strong professional culture atmosphere, to improve higher vocational students' comprehensive professional quality and ability to adapt to society is of great significance, good practice base management system, practice base and can serve the teaching, so this topic choice school experiment connotation construction of practice training bases as the object of study has great practical significance. Traditional laboratory are less actual operation, teachers, students can't tracking guidance to all students, lack of systemic and purpose. Therefore, in addition to strengthen the practice teaching, can also through the simulation of the operation and the simulation experiment teaching to improve their strain ability, garden professional mainly in garden plants and maintenance, landscape nursery stock production, the botanical garden sketch, engineering construction and management, and other factors, therefore, to establish the virtual simulation platform has important practical significance. In virtual simulation experiment teaching, let students to simulate production activities to simulate the process of production and management of operation, help to improve the students' ability of operation.

\subsection{How to $7 \mathrm{~s}$ on-site management and experiment training room management to achieve docking.}

At present, the domestic many managers and teachers in the management mechanism, the organizational structure and management system and other aspects are discussed in this paper and the research, some management concept has been done in the actual operation, and achieved good results. For the implementation of the new experiment bases management theory research, many teachers in the study of the practice teaching management analysis, combined with the actual situation of our school, puts forward the unified planning, unified construction, unified management, unified call, resource sharing, perfect function, make full use of the reform train of thought. $7 \mathrm{~s}$ on-site management attaches great importance to the efficiency, the principle of human nature and persistence, with the experiment training room management relative to meet can obtain good effect. This requires practice training management attaches great importance to the efficiency of management, help to promote the development of the experimental teaching; In addition, the establishment of expert team, establish the management direction and focus, make effective teaching management organization activities and assist teachers in teaching activities and equipment maintenance, and in strict accordance with the relevant procedures and requirements to carry out teaching activities, pay more attention to the specification of the experimental training rooms and management.

\section{Conclusion}

With the deepening of globalization, the traditional teaching mode is no longer adapt to 
the development of the society, under the background of rapid development of modern society, the experiment teaching of cultivating students' operating ability and innovation ability and teaching activities, improvement of teaching quality is an important part of . Laboratory construction as one of the school education quality evaluation standards, is an important performance of school teaching, scientific research and management, help to promote landscape engineering students the importance of theory union actual work.

\section{References}

[1] Zhang Yange, Mao Xiu yuan, yu-lan ding, etc. The nursery garden students in the construction of the experimental base for improving the employment competitiveness of research [J]. Journal of youth, 2014, 12 (8) : 176-177

Wide. [2] is high in garden "garden genetic breeding experimental teaching reform to explore" [J]. Journal of exam, 2012, 22 (63) : 19 to 20 .

[3] wu Ming, basket. On strengthening practical teaching reform for advanced vocational garden technology discussion $[\mathrm{J}]$. Chinese science and education innovation Tribune, 2012, 13 (18) : 29 and 30 .

[4] Zhang Yunlu, li xiong, benji. Institute of Beijing forestry university garden Liang $\mathrm{Xi}$ experimental classes exploration and practice of talent training mode $[\mathrm{J}]$. Chinese garden, 2015, 31 (5) : 23-26.

[5] jun-huo CAI, xu-ying wei, even aromatic green, etc. In garden "classroom, experiment and practice of the trinity" mode of teaching $[\mathrm{J}]$. Journal of higher education BBS, 2012, 14 (9) : 39-41.

[6] Zhang Jinping, Pan Yuan wisdom. Agriculture and forestry colleges and universities the landscape architectural design mode of experimental teaching $[\mathrm{J}]$. Journal of anhui agricultural science, 2012, 38 (28) :
16044-16045.

[7] car generation brother, have no opinion of eu. Gardening, landscape subject experimental teaching system, construction of exploration and practice [J]. Journal of laboratory science, 2013, 22 (6) : 3-5. 